\title{
Study of the influence of alloying elements on the mechanical characteristics and wear behavior of a ductile cast iron
}

\author{
Mohammed Iliasse Boulifa \\ University of El Oued, Fac. Technology, Dept. Mechanical Engineering 39000 El Oued, Algeria \\ Foundry Laboratory, Faculty of Engineering Sciences, BADJI Mokbtar University 23000 Annaba, Algeria \\ biliasse@gmail.com, bttp://orcid.org/0000-0001-5131-8551
}

\author{
Ali Hadji \\ Foundry Laboratory, Faculty of Engineering Sciences, Badji Mokbtar University 23000 Annaba, Algeria \\ badji.lrf@gmail.com, bttp:/ / orcid.org/0000-0001-6673-6967
}

\begin{abstract}
In the present work, the influence of alloying elements, on the mechanical characteristics and wear behavior by modification of the chemical composition of the ductile iron was studied, to improve these characteristics for the manufacture of agricultural tractors parts in particular front and rear axles, ploughshares, gear crankcase, pinions, transmission shafts, crankshafts, etc... The cast iron investigated was prepared in an induction furnace at $1500^{\circ} \mathrm{C}$ and inoculated by a ferro-silicon-magnesium to $45 \% \mathrm{Si}$ and $10 \% \mathrm{Mg}$. The specimens were casted into self-hardening sand moulds at $1450^{\circ} \mathrm{C}$, after an addition of alloying elements, Manganese $(0.6 \%)$, Nickel $(0.5 \%)$, Molybdenum $(0.2 \%)$, and $\operatorname{Vanadium}(0.1 \%)$ in the base spheroidal graphite cast iron produced. Various techniques including, optical microscopy, microhardness, hardness, tensile strength, impact resistance, and wear tests (wear resistance and friction coefficient) were used to characterize these specimens. The obtained results show that the tested samples have ductile iron structures formed by ferrite and pearlite. Moreover, mechanical and wear tests prove that the alloyed cast iron has improved characteristics compared to unalloyed cast iron and shows the positive effect of alloying elements on these characteristics.
\end{abstract}

KEYWORDS. Ductile iron; Ferrite-pearlitic matrix; Mechanical characteristics; Wear resistance; Friction coefficient.

\section{open ACcess}

Citation: Boulifa, M. I., Hadji, A., Study of the Influence of Alloying Elements on the Mechanical Characteristics and Wear Behavior of a Ductile Cast Iron, Frattura ed Integrità Strutturale, 56 (2021) 74-83

Received: 24.11.2020

Accepted: 16.02.2021

Published: 01.04.2021

Copyright: (C) 2021 This is an open access article under the terms of the CC-BY 4.0, which permits unrestricted use, distribution, and reproduction in any medium, provided the original author and source are credited.

\section{INTRODUCTION}

uctile iron is a cast iron with spheroidal graphite, so-called spheroidal graphite cast iron. It has mechanical properties that are similar to those of some steels [1]. More favourably, in contrast to cast steels, ductile iron has many technical and manufacturing advantages. These include excellent damping ability, increased wear resistance, 
$20-40 \%$ lower production costs and reduced volume shrinkage during solidification. Besides, it is superior in cost, antifrictional and damping characteristics to steel. As a result, it has been successfully used to manufacture several types of mechanical components, based on the combination of good mechanical properties and casting abilities of ductile cast iron. Especially in the automotive industry, such as gears, camshafts, connecting roads, crankshafts, gearboxes, front wheel spindle supports and truck axles, and also used for a wide variety of industrial applications, such as like pipes, flanges, pump housings, turbine components, that before had been made of steel [2-6].

In ductile iron, graphite is precipitated as spheroids rather than flakes by controlled processing of the molten iron. The graphite's circular form reduces the risk of the material to crack and helps avoid the spread of cracks. Graphite flakes serve as stress risers that initiate and propagate cracks in gray cast iron, rendering the material weaker [7-9]. Ductile iron's chemical and metallurgical characteristics make it the strongest and hardest cast iron, and also with the highest maximum durability. $[10-12]$.

A study of the production of iron makes it simple to understand the advantages of ductile iron. In a matrix of ferrite and pearlite, ferrite-pearlitic ductile iron has graphite spheroids. Pearlite is a fine ferrite and cementite (Fe3C) lamellar aggregate. With moderate ductility and high strength, the alloy is relatively hard [4,13-15].

During the design of a new material that is going to be used for structural application, mechanical properties need to be well taken into account. The development of spheroidal cast iron has reached an important place in the mechanical components industry due to its mechanical properties. The main factors that influence the mechanical properties of a ductile iron are the microstructure, the morphology of the graphite (size and nodularity), and the casting defects (shrinkage and inclusions).

The alloying elements are related to the microstructure, the matrix microstructure and mechanical properties are defined by many of these elements. Up in a particular way, the matrix microstructure affects the hardness of the cast [16,17].

The contents of alloying elements have a very important influence on the structure of the cast iron and of course on the mechanical properties. The role of alloying elements in ductile iron can be interpreted differently depending on the behavior of each element, because these elements influences mechanical properties in the same cast in a different manner. If heat treatment is not taken into account, the appropriate balance of the alloying elements must be treated carefully.

Talking about the different alloying elements in terms of the properties they confer on iron is a tradition. The ability of alloying elements to promote the formation of a certain phase or to stabilize it is a property of great importance. These elements are grouped as elements that form austenite, ferrite, carbide, and nitride [18]:

- Elements may encourage formation of graphite from the carbide. Before forming graphite, only a small proportion of these elements can be added to the iron. Silicon, nickel, cobalt, and aluminum are elements that facilitate the formation of graphite;

- Alloying elements may go into solid solution in the iron, such silicon, molybdenum, chromium, nickel, and magnesium improve strength;

- Elements which tend to form carbides include chromium, tungsten, titanium, columbium, vanadium, molybdenum, and manganese;

- Austenite stabilizing elements include manganese, nickel, cobalt, and copper. These increase the range over which austenite is stable;

- Elements, which tend to stabilize ferrite, include chromium, tungsten, molybdenum, vanadium, and silicon. They decrease the quantity of carbon soluble in the austenite and thus increase the quantity of free carbide in the iron at a given carbon content.

Recent research works [13,15,19-24] have shown that, Si, Mn, Ni, Mo, V, Cu, Ti, Nb, W, Sn... are the typical alloying elements used to control ferrite and pearlite contents and increases mechanical properties in ductile iron as-cast grades. Mn and $\mathrm{Cu}$ are used to promote pearlite, $\mathrm{Si}$ is used to promote ferrite and to strengthen it. When producing the pearlitic grades, $\mathrm{Si}$ is usually must be below $2.5 \%$ and when developing ferritic grades, it is between 2.5 and $2.8 \%$. When making pearlitic grades, the rate of $\mathrm{Mn}$ is generally between 0.4 and $0.6 \%$ and below $0.3 \%$ when making ferritic grades. According to these research works, it can noted that:

Silicon is considered as an alloying element if its content exceeds $3 \%$, it easily forms solid solutions with cast iron. It has a certain effect to avoid grain enlargement. Silicon alloyed with iron, widens ferrite phase domain. It increases the stability, wear resistance, and the yield strength, as it greatly increases the fluidity of the cast iron.

- Manganese greatly reduces the critical cooling rate. It thus increases the hardness, yield strength, and tensile strength, decreasing elongation and improving toughness. If its content varies from 5 to $12 \%$, it favors the formation of martensitic structure. If its content exceeds $12 \%$, then the structure becomes austenitic.

- Nickel gives the metal a set of remarkable properties so that it is used in all kinds of applications. The effect of nickel only occurs when it is used together with other elements. It allies completely with the austenite, forming a 
continuous series of solid solutions. Addition of Ni improves hardness. Nickel has a similar behavior to manganese. Its fundamental interest is to lower the temperature of critical points.

- Molybdenum is used in combination with Ni and/or Cu. It improves hardenability and decreases the critical cooling rate. It increases the yield strength, tensile strength, and wear resistance. It improves machinability, impact resistance, and fatigue resistance properties. Mo gives the cast iron good fluidity. The improvement in properties, due to molybdenum, is also because it lowers the temperature of critical points.

- Vanadium is a powerful generator of carbides, hence it increases wear resistance. It is an element, which has the effect of stabilizing the carbides. It is used to compensate, in certain alloyed cast irons, containing elements encourage formation of graphite from the carbide (nickel-titanium). Vanadium is a deoxidizing element, it is used in order to obtain very healthy cast irons.

- Copper dissolves in the ferrite, the addition of copper has not a direct influence on the hardness, only if the dimensions of the parts are not important. It increases tensile strength and yield strength. Cu contents superior at $0.30 \%$ may cause structural hardening improving hardenability.

- Titanium has grain refining properties, which increases the value of mechanical characteristics and causes a reduction of the austenite zone. Titanium has a very noticeable effect on graphite it makes it very thin.

- Niobium is a very powerful generator of carbides and ferrite while reducing the austenite zone. It increases hardness, tensile strength, yield strength, and refines the grains.

As is known, many factors can affect the wear performance of a material. The microstructure and the nature of the material are extremely important among these factors. Depending on the composition, the matrix structure of ductile iron can be ferritic, pearlitic, bainitic, or martensitic [13-16].

One of the most commonly encountered industrial problems is wear, particularly through abrasion, leading to frequent replacement of components. Abrasive wear occurs when hard particles or asperities penetrate a softer surface and displace material in the form of elongated chips and slivers. During the wear process, the hard particles can be formed inside the tribosystem itself or they can be contaminated by the environment. Wear resistance is not an intrinsic material property, but relies on the tribological mechanism, such as material microstructure properties, abrasive grit size, test condition, equipment, and environment [25-27].

Friction and wear are subject to many mechanical components, which makes this iron very interesting from the point of view of tribological behavior. Several researchers have studied the sliding wear action of cast iron. The wear resistance of the ductile iron under dry sliding conditions is superior than that of the same steels of the same hardness. They have also reported that the wear loss is related to the original hardness (before the wear test) under dry sliding conditions using the pin-on-disk machine [28,29].

During these last few years, ductile iron is the subject of a wide variety of studies, both on transformation theory, on the fields of application, and on the mechanical properties. Currently, research efforts on this cast iron are mainly concentrated on possible improvements in its mechanical properties. The problems to be studied are the thermal and thermo-mechanical stability of the structure, the influence of alloying elements on the mechanical properties, the influence of heat treatment parameters on the structure, and on the state of the residual stresses...

The main objective of the present research is to improve the properties of this cast iron, also to investigate the correlation between microstructure and these properties. This is why we took as research axes, the choice of alloying elements to be added, their contents, and their influence on the mechanical properties and wear resistance. In other words, this research has been done with the aim of analyzing the behavior of the casting from the variation of the chemical composition and its effect on the mechanical properties and wear behavior. With it, we want to reaffirm the role and the importance that the appropriate control of each alloying element introduced in the spheroidal graphite cast iron. This last is characterized by the end zones of solidification less rich in silicon, where there are the porosities, first responsible sites at initiation of fatigue cracks.

The base metal (unalloyed cast iron) presented in this research is an industrial ductile cast iron actually used for the production of mechanical parts, in an agricultural tractor society, which has well-defined mechanical properties. The best mechanical properties such as microhardness, hardness, yield strength, tensile strength, elongation, impact resistance and wear resistance were found based upon various structural and mechanical characterizations based upon alloying elements such as Mn, Ni, Mo and V added in the base metal. Many of these elements define the matrix microstructure and mechanical properties. These alloying elements added to nodular irons are of particular interest for the manufacturing of mechanical parts, because of benefits to the resulting mechanical properties. Ductile iron constitutes alloyed ferrite and perlite in the matrix, this microstructure confers a high strength with favourable hardness. 


\section{EXPERIMENTAL PROCEDURES}

\section{$\mathrm{I}$}

Casting procedure $\mathrm{n}$ this experimental work, the specimens used to study the ductile cast iron were obtained in an industrial foundry, by casting the melt in cold self-hardening sand moulds at $1450^{\circ} \mathrm{C}$, in form of $50 \mathrm{~mm}$ Y-blocks according to dimensions specified in ISO 1083-76 standard [30]. For $100 \mathrm{Kg}$ of base metal (ductile iron) heats comprising of $70 \mathrm{Kg}$ of pig iron, $20 \mathrm{Kg}$ returns and $10 \mathrm{Kg}$ of steel scrap were prepared in an induction furnace with a maximum capacity of $3000 \mathrm{~kg}$ at 1500 ${ }^{\circ} \mathrm{C}$. The spheroidization process was performed by the sandwich method using a $\mathrm{Fe}-\mathrm{Si}-\mathrm{Mg}$ alloy $(45 \% \mathrm{Si}$ and $10 \% \mathrm{Mg}$ ). From the base composition, an alloyed material was studied: $0.6 \% \mathrm{Mn}, 0.50 \% \mathrm{Ni}, 0.20 \% \mathrm{Mo}$, and $0.10 \% \mathrm{~V}$. The rate of $\mathrm{Mn}$ added (element which tends to form carbides) is to stabilize austenite, increase the hardenability, favour the formation of precipitates, and consequently improving the mechanical properties and wear behavior. Concerning the level of $\mathrm{Ni}$ (element may encourage formation of graphite from the carbide and go into solid solution in the iron), this is to stabilize austenite on one side, neutralize the adverse effect of $\mathrm{Mn}$ notably graphite degeneration and the formation of the white structure on the other side. Molybdenum and vanadium were introduced to stabilize ferrite and increase strength.

The chemical composition analysis of the unalloyed (base metal) and alloyed cast irons was determined using a fluorescence spectrometer X. The results of this analysis are shown in Tab. 1.

\begin{tabular}{ccccccccc}
\hline Cast irons & $\mathrm{C}(\%)$ & $\mathrm{Si}(\%)$ & $\mathrm{Mn}(\%)$ & $\mathrm{P}(\%)$ & $\mathrm{S}(\%)$ & $\mathrm{Ni}(\%)$ & $\mathrm{Mo}(\%)$ & $\mathrm{V}(\%)$ \\
Unalloyed & 3.39 & 2.175 & 0.08 & 0.008 & 0.0018 & 0.007 & 0.00 & 0.06 \\
Alloyed & 3.39 & 2.175 & 0.638 & 0.008 & 0.0018 & 0.507 & 0.20 & 0.16 \\
\hline
\end{tabular}

Table 1: Chemical composition of experimented cast irons (wt. \%).

\section{Microstructural examination}

The microstructure analysis was carried out using an optical microscope (NIKON Eclipse LV100ND type). The samples were polished and chemically attacked at $3 \%$ nital.

\section{Mechanical tests}

The specimens were cut from Y-blocks to different shapes according to the test type. A Vickers microhardness tester "Zwick/ROELL ZHV10" type was used. The tests were carried out using $0.1 \mathrm{~kg}$ load and 15 second period of loading. The method used for measuring hardness was "HRB". Six tests were performed for each specimen of microhardness and hardness and the average was taken. Tensile tests were performed at a strain rate of $8 \times 10^{-3} \mathrm{~s}^{-1}$ on a "Zwick / ROELL Z100" testing machine. Three samples were tested for each cast iron and the average was taken. The tests were carried at $20^{\circ} \mathrm{C}$ according to the ISO 1083-76 standard. Impact resistance was measured by Charpy impact test using a "SINTCO" type machine. Tests were carried at $20^{\circ} \mathrm{C}$ using notched specimens according to the ISO 1083-76 standard. Three experimental tests were carried out for each sample. The calculated average of these three measures reflected the impact resistance.

\section{Wear tests}

The sliding wear tests were carried out using a pin-on-disc method at room temperature according to the ASTM-G99 standard. The weight loss of material was determined after a passage of the specimen on a disk, on which a silicon carbide abrasive paper ( 800 grit) was fixed. It travels a total distance of $420 \mathrm{~m}$ at 80 rotations per minute. The test was performed using an applied normal load of $12 \mathrm{~N}$. $6 \mathrm{~mm}$ diameter and $10 \mathrm{~mm}$ long specimens were used for the test. After an initial run of $6 \mathrm{~min}$ for each specimen, the weight was measured using a $0.1 \mathrm{mg}$ precision scale. After wear test, each specimen was weighed to determine the weight loss. Three experimental tests for each sample were carried out. The weight loss was represented by the calculated average of these three tests [31,32].

The variation of friction coefficient test was carried out on the prepared specimens, two wear tests were performed using a ball-on-disk apparatus under two loads $(5 \mathrm{~N}$ and $10 \mathrm{~N}$ ) at $0.5 \mathrm{~m} / \mathrm{s}$ sliding speed and $100 \mathrm{~m}$ sliding distance. The ball specimen was made of steel $(100 \mathrm{Cr} 6)$ with a diameter of $6 \mathrm{~mm}$ and hardness of $61 \mathrm{HRC}$. Before the test, the samples were ground with abrasive paper (2400 grit), polished and cleaned with alcohol [33]. 


\section{RESULTS AND DISCUSSION}

\section{Microstructural Analysis}

1 he metallographic study shows that the structure of the unalloyed cast iron (Fig. 1) is formed by ferrite and pearlite where the ferrite surrounds graphite nodules. This structure has a ferrite rate more important than that the pearlite.

1 The morphology of graphite nodules is wholly spherical.
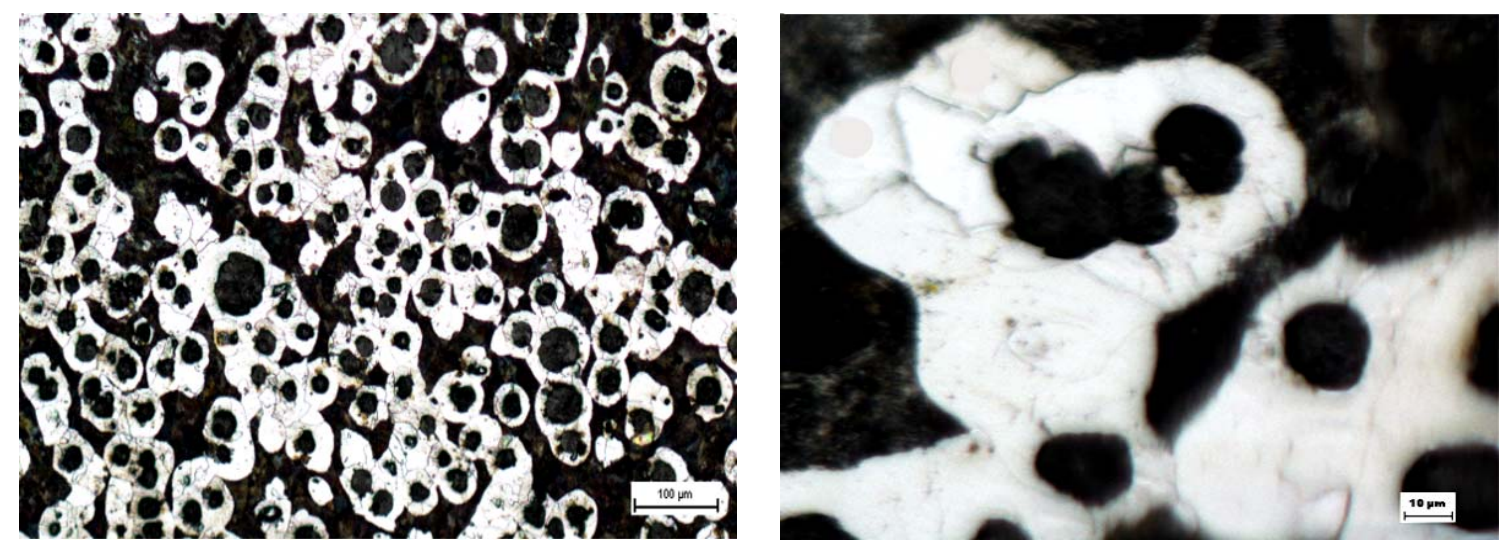

Figure 1: Microstructures of unalloyed cast iron in the cast condition.

The alloyed cast iron (Fig. 2) has a ferrite-pearlitic structure. Compared to the unalloyed cast iron, the alloyed cast iron structure exhibits an increase in the quantity of pearlite. This is due to high rates of $\mathrm{Ni}(0.5 \%)$ and $\mathrm{Mn}(0.6 \%)$. The morphology of graphite nodules in the microstructure of the cast iron is entirely spherical, it is not influenced by carbideforming elements. The refining effect of alloying elements ( $\mathrm{Mn}$ and $\mathrm{Ni}$ ) is also observed compared to unalloyed cast condition. Ni delays the coarsening of austenite grains and so refines the microstructure. Concerning the graphite, the morphology of nodules in the microstructure of the cast iron always remains entirely spherical.
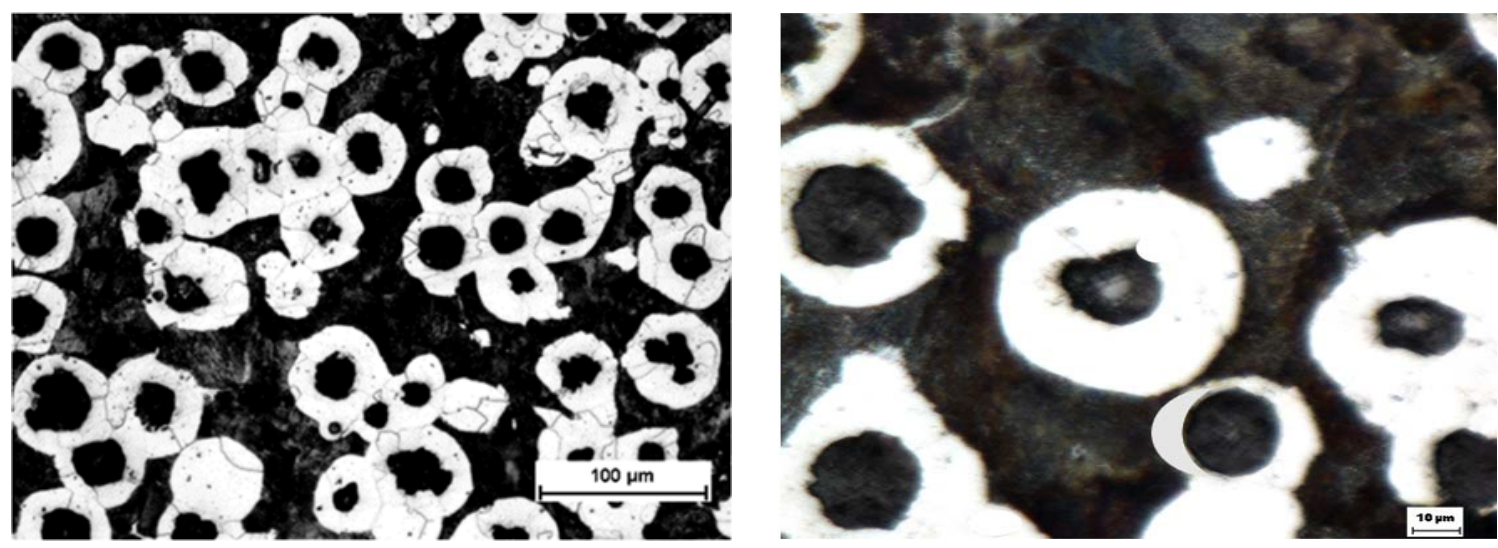

Figure 2: Microstructures of alloyed cast iron in the cast condition.

\section{Microbardness}

The results obtained show sufficiently the influence of alloying elements on cast irons produced in a positive manner, because of the change in structure on the one hand and increase the properties on the other hand (Tab. 2). Microhardness measurements of microstructural constituents of the unalloyed cast iron have given a ferrite of $132 \mathrm{HV}$ (the standard deviation is $1.41 \mathrm{HV}$ ) and perlite of $214 \mathrm{HV}$ (the standard deviation is $1.41 \mathrm{HV}$ ). For alloyed cast iron, the microhardness of the ferrite is $166 \mathrm{HV}$ (the standard deviation is $1.41 \mathrm{HV}$ ) and $282 \mathrm{HV}$ for pearlite were the standard deviation is $2.16 \mathrm{HV}$. An increase in the microhardness of various microstructural constituents is observed in alloyed cast iron, compared with unalloyed cast iron. This can be explained by a manganese content introduced $(0.6 \%)$ and that of nickel $(0.5 \%)$. 


\section{Hardness}

The hardness results obtained show the influence of alloying elements on cast irons elaborated in a positive manner because of the remarkable increase of this property after addition of the alloying elements. The results are presented in Tab. 2. The hardness of the unalloyed cast iron is $95 \mathrm{HRB}$ (the standard deviation is $1.41 \mathrm{HRB}$ ). After the addition of alloying elements in this cast iron, there is a remarkable increase in hardness (99 HRB with a standard deviation is $1.82 \mathrm{HRB}$ ). Compared to the unalloyed cast iron, the hardness of alloyed cast iron is greater, this is due to the addition of $\mathrm{Mn}, 0.6 \%$ and Ni, $0.5 \%$. The increase of the hardness is probably due to structural hardening following the dissolution of the alloying elements in the solid solutions or by the formation of precipitates.

\begin{tabular}{cccc}
\hline Cast irons & \multicolumn{2}{c}{$\begin{array}{c}\text { Microhardness } \\
(\mathrm{HV})\end{array}$} & $\begin{array}{c}\text { Hardness } \\
\text { (HRB) }\end{array}$ \\
& ferrite & pearlite & \\
Unalloyed & 132 & 214 & 95 \\
Alloyed & 166 & 282 & 99 \\
\hline
\end{tabular}

Table 2: Microhardness and hardness results.

\section{Tensile proprieties}

The results of the Young's modulus, yield strength, tensile strength and elongation are shown in Tab. 3. The young's modulus of unalloyed cast iron is $171 \mathrm{GPa}$ with a standard deviation is $2.16 \mathrm{GPa}$ and that of alloyed cast iron is $175 \mathrm{GPa}$ with a standard deviation is $2.94 \mathrm{GPa}$. The yield strength of the unalloyed cast iron is $530 \mathrm{MPa}$ were the standard deviation is $2.16 \mathrm{MPa}$. An increase $(560 \mathrm{MPa}$ with a standard deviation is $7.11 \mathrm{MPa}$ ) is observed for alloyed cast iron following the addition of $\mathrm{Ni}(0.5 \%), \mathrm{Mn}(0.6 \%), \mathrm{Mo}(0.2 \%)$ and $\mathrm{V}(0.1 \%)$. The tensile strength of the unalloyed cast iron is $710 \mathrm{MPa}$ (the standard deviation is $3.55 \mathrm{MPa}$ ). The growth of the resistance of alloyed cast iron to $750 \mathrm{MPa}$ (the standard deviation is 7.25 $\mathrm{MPa}$ ) is due to the addition of $0.6 \% \mathrm{Mn}$ and $0.5 \% \mathrm{Ni}$. These two elements improve the hardenability of cast iron and therefore promote this increase. The results of elongation of the different cast iron experimented shows that this property of the unalloyed cast iron is higher $(4.63 \%$ with a standard deviation is $0.17 \%)$. The elongation of alloyed cast iron $(3.0 \%$ with a standard deviation is $0.71 \%$ ) has decreased relative to the unalloyed cast iron. This shows that the elevation of the different elements favoured a structural hardening, which explains this clear regression in ductility. The increase in young's modulus, yield strength, tensile strength and the decrease in elongation observed in alloyed cast iron compared to unalloyed cast iron can be explained by the structural hardening. This is as in the case of hardness, following the dissolution of the alloying elements in the solid solutions or by the formation of precipitates.

\section{Impact resistance}

The results of the impact resistance of ductile cast iron are illustrated in Tab. 3. The unalloyed cast iron has an impact resistance of $6.12 \mathrm{~J} / \mathrm{cm}^{2}$ (the standard deviation is $0.17 \mathrm{~J} / \mathrm{cm}^{2}$ ). This characteristic achieved $8.5 \mathrm{~J} / \mathrm{cm}^{2}$ (the standard deviation is $0.50 \mathrm{~J} / \mathrm{cm}^{2}$ ) for alloyed cast iron is due to the addition of $0.2 \% \mathrm{Mo}$ and $0.1 \% \mathrm{~V}$. These elements create precipitates that cause structural hardening.

\begin{tabular}{cccccc}
\hline Cast irons & $\begin{array}{c}\text { Young's modulus } \\
(\mathrm{GPa})\end{array}$ & $\begin{array}{c}\text { Yield strength } \\
(\mathrm{MPa})\end{array}$ & $\begin{array}{c}\text { Tensile strength } \\
(\mathrm{MPa})\end{array}$ & $\begin{array}{c}\text { Elongation } \\
(\%)\end{array}$ & $\begin{array}{c}\text { Impact resistance } \\
\left(\mathrm{J} / \mathrm{cm}^{2}\right)\end{array}$ \\
Unalloyed & 171 & 530 & 710 & 4.63 & 6.12 \\
Alloyed & 175 & 560 & 750 & 3.0 & 8.5 \\
\hline
\end{tabular}

Table 3: Tensile proprieties and impact resistance results.

Wear behavior: wear resistance

The wear tests were conducted on both of cast irons. The weight loss results presented in Tab. 4, show that the weight loss of the unalloyed sample is $0.043 \mathrm{~g}$ (the standard deviation is $0.004 \mathrm{~g}$ ), while for the alloyed cast iron sample is $0.025 \mathrm{~g}$ (the 
standard deviation is $0.003 \mathrm{~g}$ ). This result is explained by an improvement of the wear resistance of the studied cast iron. Alloying elements favours the formation of an enriched solid solution and different precipitates, which increase the hardness and the wear behavior of the cast iron under study. The wear mechanism occurs in this case is based on three factors. The first one is the applied load. Increasing of the latter leads to an acceleration of the sliding wear of the iron. The second factor is related to the microstructure and the properties of the cast iron. The presence of ferrite in the matrix, ductile phase decrease the hardness of the cast iron and increases its wear rate. The last factor is the graphite, this phase is known for its less resistance to elastic strain caused by wear stresses [31,32].

\section{Wear behavior: friction coefficient}

The friction coefficient presented in Tab. 4 of the unalloyed cast iron is 0.388 (standard deviation is 0.067 ) for $5 \mathrm{~N}$ and 0.426 (standard deviation is 0.093 ) for $10 \mathrm{~N}$. While for the alloyed cast iron is 0.303 (standard deviation is 0.097 ) for $5 \mathrm{~N}$ and 0.324 (standard deviation is 0.099 ) for $10 \mathrm{~N}$. It is noticed that the friction coefficient increases with the applied load for the two cast irons (unalloyed and alloyed). The coefficient of friction of alloyed cast iron is lower than that of unalloyed cast iron for both loads $5 \mathrm{~N}$ and $10 \mathrm{~N}$. Also, the alloyed cast iron is more resistant to friction compared to unalloyed cast iron for both forces. This decrease is explained by the refinement of the structure, caused by the addition of alloying elements in the alloyed cast iron compared to the unalloyed cast iron. A fine structure favours a high resistance to friction, which reduces the friction coefficient. The ferrite, which surrounds the graphite in the alloyed cast iron is finer than that formed in the unalloyed cast iron coarser.

The graphs of the unalloyed cast iron (Fig. 3) are more fluctuated for the two applied loads (5 and $10 \mathrm{~N}$ ). This is due to the heterogeneity of the microstructure of this metal. The formation of a coarse perlite phase distributed heterogeneously in the structure, leads to more of fluctuations. On the other hand, the friction coefficient of the alloyed cast iron (Fig. 4) presents less fluctuations compared to the unalloyed cast iron, this is explained by the enrichment of the perlite with manganese, nickel, molybdenum and vanadium, which hardened it.

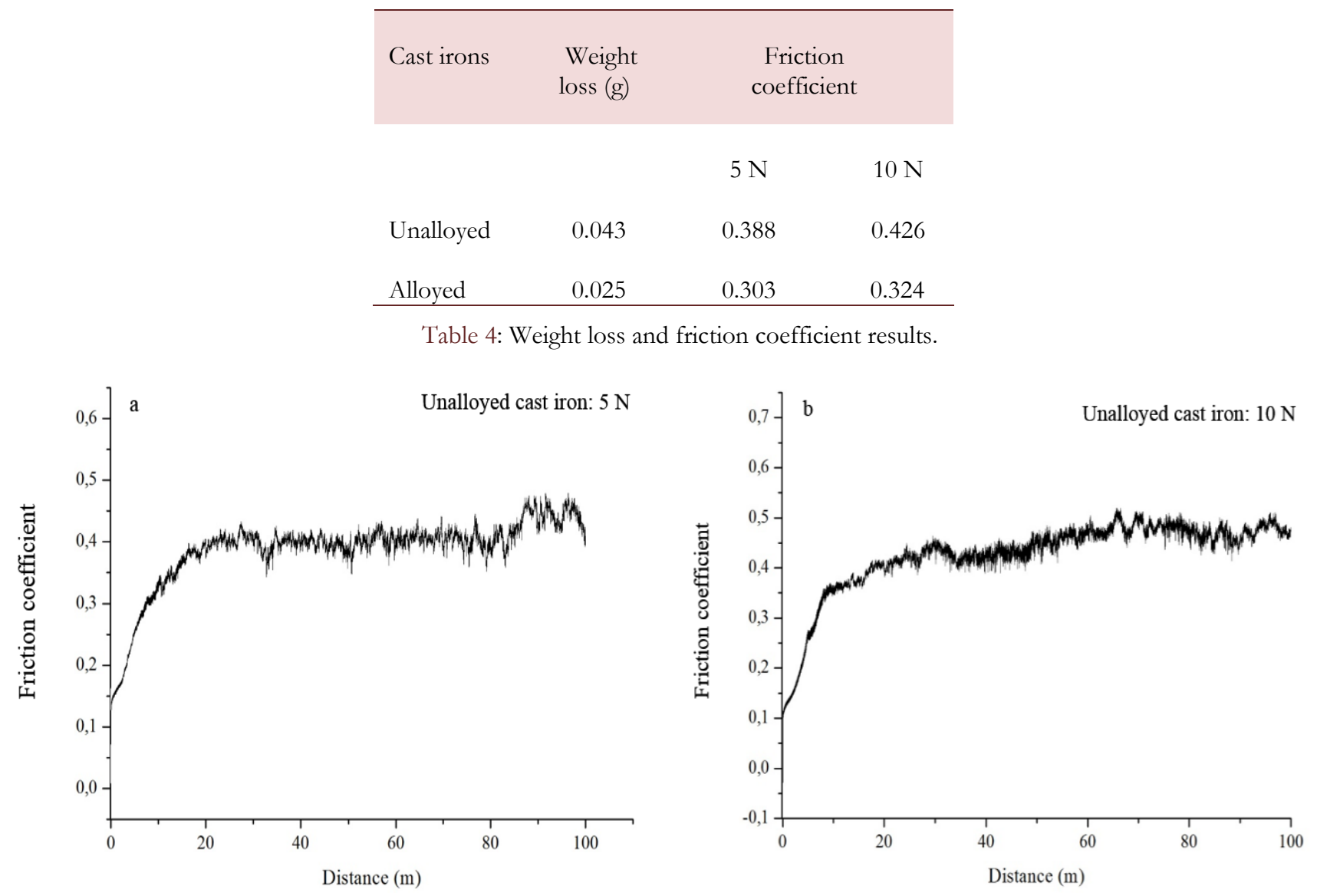

Figure 3: Friction coefficient of unalloyed cast iron; a: $5 \mathrm{~N}$, b: $10 \mathrm{~N}$. 

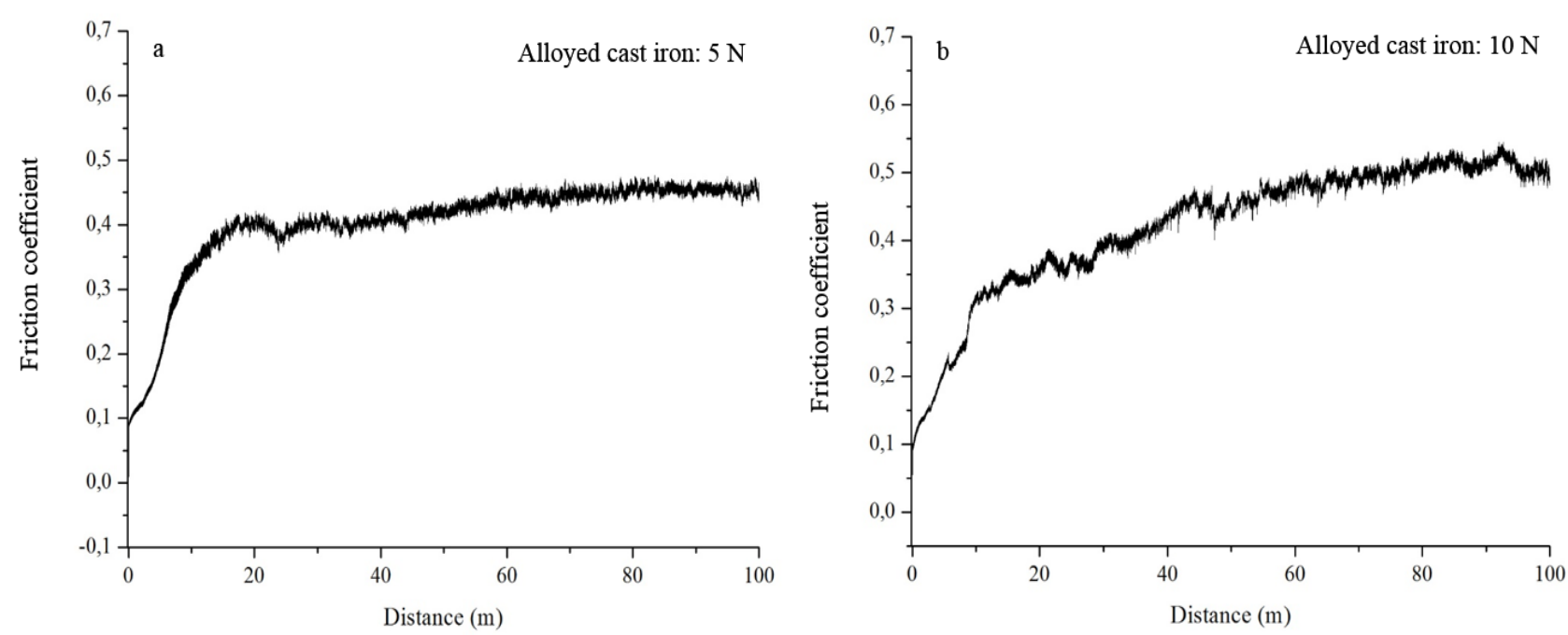

Figure 4: Friction coefficient of alloyed cast iron; a: $5 \mathrm{~N}$, b: $10 \mathrm{~N}$.

\section{CONCLUSION}

uctile cast iron alloyed to Manganese (0.6\%), Nickel (0.5\%), Molybdenum $(0.2 \%)$ and Vanadium $(0.1 \%))$ was produced aiming to replace the unalloyed ductile iron.

The effect of alloying elements on the mechanical characteristics and wear behavior (wear resistance and friction coefficient) was studied.

According to this study, it can be concluded that:

1. The optical microscope observation shows that the samples have structures formed of ferrite and pearlite. The alloyed cast iron structure shows an improvement in the amount of pearlite relative to the unalloyed cast iron.

2. The results of mechanical tests and wear behavior show in the whole that the cast irons studied achieve higher properties. Hardness and microhardness are increased in a remarkable way for alloyed cast iron, compared to the unalloyed cast iron.

3. The sample of the alloyed cast iron has reached a higher tensile strength than that of the unalloyed cast iron with an important ductility. The same ascertainment can be made for the impact resistance.

4. For the wear tests, it is noted that the weight loss and the friction coefficient decrease with the addition of the alloying elements compared to the unalloyed cast iron. It thus influenced in a positive way by the addition of these elements.

5. Alloyed ductile cast iron formed by ferrite-pearlitic structures. There are therefore several advantages to using this cast iron in many fields of engineering.

\section{ACKNOWLEDGEMENT}

A uthors gratefully acknowledge Agricultural tractor society (ETRAG CONSTANTINE) for permitting to conduct the melting and casting. In addition, we thanks Pr. TOUHAMI Med Zine, Pr. MECHACHTI Said, Dr.

MAOUCHE Hichem, and Dr. AYADI Souad (Metallurgy and Materials Engineering Department, University of ANNABA) for their assistance in characterization of specimens.

\section{REFERENCES}

[1] Xiang Ru, C., Qi Jie, Z., Han, D., Bao Hua, D. and Hardy M. (2020). Molybdenum alloying in cast iron and steel, Adv. Manuf., 8, pp. 3-14. DOI: 10.1007/s40436-019-00282-1. 
[2] Bok Gyu L., Kyong Ho S., and Ryong Chol K. (2018). Effect of Sb-Ba-Ce-Si-Fe Post Inoculants on Microstructural and Mechanical Properties of As-Cast Pearlitic Ductile Iron, Steel research int., 90(5), pp. 1-6. DOI: 10.1002/srin.201800530.

[3] Mohd Nadeem, B., Afzal Khana, D.M. and Singh, K.K. (2018). Effect of inoculation and nodularisation treatment temperature on recalescence and eutectic undercooling temperature in Spheroidal graphite (SG) cast iron, International Journal of Cast Metals Research, 31(5), pp. 261-268. DOI: 10.1080/13640461.2018.1434987.

[4] Rodolfo, G.M., Urko de la, T., André, E., Jacques, L. and Jon, S. (2018). Effects of high silicon contents on graphite morphology and room temperature mechanical properties of as-cast ferritic ductile cast irons. Part II-Mechanical properties, Materials Science \& Engineering A 712, pp. 803-811. DOI: 10.1016/j.msea.2017.11.051.

[5] Moritz, R., Hergen Groß, S., Bjo“rn, P., and Andreas, B.P. (2018). Influence of carbide-promoting elements on the pearlite content and the tensile properties of high silicon SSDI ductile iron, Inter Metalcast, 12, pp. 106-112. DOI: $10.1007 /$ s40962-017-0146-7.

[6] Costanzo, B., Vittorio Di, C., Gregory, F., Francesco, I. and Luca, S. (2019). Ductile cast irons: Microstructure influence on the fatigue initiation mechanisms, Fatigue and Fracture of Engineering Materials Structure, 42(9), pp. 1-11. DOI: $10.1111 /$ ffe. 13100 .

[7] Jacques, L. (2017). Trace elements and graphite shape degeneracy in nodular graphite cast irons, Inter Metalcast, 11(1), pp. 44-51. DOI: 10.1007/s40962-016-0115-6.

[8] Gorka, A., Doru, M. S., Esther De la, F., Pello, L. and Ramon, S. (2018). The Influence of Trace Elements on the Nature of the Nuclei of the Graphite in Ductile Iron, Materials Science Forum, 925, pp. 78-85. DOI:10.4028/www.scientific.net/MSF.925.78.

[9] Wolfram, B. (2020). Chunky graphite in ferritic spheroidal graphite cast iron: formation, prevention, characterization, impact on properties: an overview, Inter Metalcast, 14, pp. 454-488. DOI: 10.1007/s40962-019-00363-8.

[10] Jose Florentino, A. A. and Juan, A.L. (2017). Optimization of the mechanical behaviour under tensile stress of spheroidal cast iron with ferritic matrix used in the manufacture of wind turbine hubs, Inter Metalcast, 11, pp. 513522. DOI: $10.1007 / \mathrm{s} 40962-016-0100-0$.

[11] Wolfram, S., Herbert, L., Gert, G. and Peter, S. (2014). Solution strengthened ferritic ductile cast iron Properties, production and application, Inter Metalcast, 8(2), pp.35-40. DOI: 10.1007/BF03355580.

[12] Murcia, S.C., Paniagua, M.A. and Ossa, E.A. (2013). Development of as-cast dual matrix structure (DMS) ductile iron, Materials Science \& Engineering A 566, pp. 8-15. DOI: 10.1016/j.msea.2012.12.033.

[13] Laura, N.G., Alfredo, J.T., Fernando, D.C. and Roberto, E.B. (2019). Identification of Cu-rich precipitates in pearlitic spheroidal graphite cast irons, Materials Science and Technology, 35(18) pp. 2252-2258. DOI: 10.1080/02670836.2019.1668999.

[14] Kalle, J., Jarkko, L., Joona, V., Tero, F. and Juhani, O. (2020). Investigation on dynamic strain aging behaviour of ferritic-pearlitic ductile cast irons, Materials Science and Technology, 36(2), pp. 160-167. DOI: 10.1080/02670836.2019.1685760.

[15] Hartung, C., Eivind, Hoel, G., Emmanuelle, O., Logan, R., Andy, P. and David, W. (2020). Research on solution strengthened ferritic ductile iron (SSFDI) structure and properties using different treatment and inoculation materials, Inter Metalcast, 14, pp. 1195-1209. DOI: 10.1007/s40962-020-00469-4.

[16] Jarkko, L., Vaara, J., Jalava, K., Soivio, K. and Orkas, J. (2020). The mechanical properties of ductile iron at intermediate temperatures: the effect of silicon content and pearlite fraction, Inter Metalcast, DOI: 10.1007/s40962-020-00473-8.

[17] Regordosa, A., de la Torre, U., Loizaga, A., Sertucha, J. and Lacaze, J. (2020) Microstructure changes during solidification of cast irons: effect of chemical composition and inoculation on competitive spheroidal and compacted graphite growth, Inter Metalcast, 14, pp. 681-688. DOI: 10.1007/s40962-019-00389-y.

[18] Mok, C.M. (2008). Effect of steel alloying elements, In: Effects of Alloying Elements on Iron Carbon Alloy, USA, NDT solution, pp. 58-93.

[19] Bakhshinezhad, H., Honarbakhshraouf, A., and Abdollah-Pour, H. (2019). A Study of Effect of Vanadium on Microstructure and Mechanical Properties of As-Cast and Austempered Ductile Iron, Physics of Metals and Metallography, 120(5), pp. 441-446. DOI: 10.1134/S0031918X19050016.

[20] Abdul, R., Jian-xin, Z., Talib, H., Zhi-xin, T., Ya-jun, Y., Xiao-yuan, J., Gen, X., and Xu, S. (2019). Effect of alloying elements W, Ti, Sn on microstructure and mechanical properties of gray iron 220, Research \& Development, 16(6), pp. 393-398. DOI: 10.1007/s41230-019-9035-4.

[21] Branko, B., Ivana Mihalic, P., Mitja, P. and Primož, M. (2018). Effect of Si and Ni Addition on Graphite Morphology in Heavy-Section Spheroidal Graphite Iron Parts, Materials Science Forum, 925, pp. 70-77. DOI: 10.4028/www.scientific.net/MSF.925.70. 
[22] Barnabas, A.A., Oyetunji, A. and Seidu, S.O. (2019). Microstructural Characterization of Antimony Modified Carbidic Austempered Ductile Iron, Journal of Materials Science Research, 8(2) pp.36-48. DOI:10.5539/jmsr.v8n2p36.

[23] Nikša, C., Dražen, Ž. and Zvonimir, D. (2018). The Effects of Molybdenum and Manganese on the Mechanical Properties of Austempered Ductile Iron, Tehnički vjesnik (Technical Gazette), 25(2), pp. 635-642. DOI: 10.17559/TV20170124120729.

[24] Sining, P., Fanzheng, Z., Nanguang, S. and Zhaokun, X. (2020). The effect of niobium addition on the microstructure and properties of cast iron used in cylinder head, J Mater Res Technol., 9(2) pp. 1137-2610. DOI: 10.1016/j.jmrt.2019.11.076.

[25] Ahmet, A. (2019). An Experimental Study on Comparison of Wear Properties of Cast Irons with Compacted Graphite and Spheroidal Graphite, Trans Indian Inst Met, 72, pp. 2257-2262. DOI: 10.1007/s12666-019-01673-5.

[26] Laguna-Camacho, J.R., Juárez-Morales, G., Calderón-Ramón, C., Velázquez-Martínez, V., Hernández-Romero, I., Méndez-Méndez, J.V. and Vite-Torres, M. (2015). A study of the wear mechanisms of disk and shoe brake pads, Engineering Failure Analysis, 56, pp. 348-359. DOI: 10.1016/j.engfailanal.2015.01.004.

[27] Lyu, Y. (2019). Abrasive Wear of Compacted Graphite Cast Iron with Added Tin. Metallogr. Microstruct. Anal. 8, pp. 67-71. DOI: 10.1007/s13632-018-0504-8.

[28] Kim, K., Yoon, M. J. (2015). Characterisation of friction behaviour of flake, spheroidal, and compacted vermicular graphite cast irons, Int J Surf Sci Eng, 9(1), pp.1-12. DOI: 10.1504/IJSURFSE.2015.067035.

[29] Bedolla-Jacuinde, A., Guerra, F.V., Rainforth, M., Mejía, I. and Maldonado, C. (2015). Sliding wear behavior of austempered ductile iron microalloyed with boron, Wear, 330-331, pp. 23-31. DOI: 10.1016/j.wear.2015.01.004.

[30] Romany, R.M., Amer, E. A., Ragab K. A., Mohamed N. E. (2019). An Investigation into Mechanical Properties of Ductile Cast Iron with Different Heat Treatment Processes, Periodica Polytechnica Mechanical Engineering, 63(3), pp. 183-187. DOI: 10.3311/PPme.13672.

[31] Boulifa, M I. and Hadji, A. (2015). Effect of alloying elements on the structure and mechanical properties of austempered ductile irons, Metall. Res. Technol. 112(4), 404 pp.1-9. DOI: 10.1051/metal/2015022.

[32] Boulifa, M.I. and Hadji, A. (2015). Effect of alloying elements on the mechanical behavior and wear of austempered ductile iron, Mechanics \& Industry 16(3), 304 pp. 1-6. DOI: $10.1051 / \mathrm{meca} / 2015002$.

[33] Ayadi, S. and Hadji, A. (2019). Effect of heat treatments on the microstructure and wear resistance of a modified Hadfield steel. Metallofiz. Noveishie Tekhnol 41(5), pp. 607-620 DOI: 10.15407/mfint.41.05.0607. 